says (what I avoided stating, although strongly suspecting it), that Hahnemann was accused " of trying to make money by false representations;" and Hahnemann's own account of the transaction is to the effect that he might have got " at least as much in the way of honorarium" by publishing a big book on

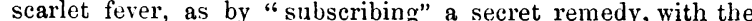
promise of a little book in the future! The reviever further discovers that the price "could not have been more than a shilling;" a statement for which he gives no authority, but which reminds me of the wet nurse's answer, when asked if her child was not illegitimate, "Yes, ma'am, but it's a very little one !"'

Surely this is very lamentable, if it were not somewhat too ludicrous. A remedy is advertised, in regard to which the professed discoverer makes strong statements as to its efficacy in the then reigning epidemic. It is said to be a preventive remedy, as powerful against scarlet fever as vaccination is against small-pox (vaccination having just then come into fashion ); trial is demanded on the double ground of humanity and science; professional opinion is formally invited; only, the disinterested discoverer must have your opinion (and your money) before he publishes the name of the remedy! Yes, says the reviewer, that is all true; but observe how very small the sum - "only a shilling"- " actually nothing"-" simpleminded confiding man"-"Alas! he little knew medical human nature !"-" child-like simplicity"-" much-abused and persecuted sage"- "open candid character"-" pure philanthropy and zeal, etc., etc.!" Such is homœopathic criticism.

The reviewer's commentary upon this most discreditable passage in Hahnemann's career, extends to no less than seven pages: but he does not eren attempt to overthrow one of my statements as to matters of fact, while he embodies his own opinion in such vague euphuisms as I have quoted above. The very application of these terms to such a transaction, is a thin so shameful, that I will not venture to characterise it. The reviewer knows perfectly well what he is about, and betrays no small amount of controversial skill in mystifying and confusin the reader as to the merits of the case. But there is one answer to all his studiously distorted representations. To have no secrets about remedies is a rule among physicians with out any exception; and in Hahnemann's case there was not even the shadow of an honourable reason for the breach of the rule. 'The reviewer's defence of Hahnemann, such as it is, resolves itself simply into a defence of nostrum-vending "I do not give you the name of the substance," he makes Hahnemann say, "as that might prejudice your judgment, or you might prepare it improperly, so I prefer sending it to you in the form in which I have found it successful. The name will be, by and bye, published, etc., etc." No one can fail to see in what direction this defence tends. The whole army of advertising quacks may shelter themselves beneath it. To rail at the medical profession for not seeing the matter in this light, is simply to appeal from honest professional opinion to the most ignorant prejudices on the part of the public.

When I proposed to myself to write a notice of Hahnemann's career, in conjunction with that of Paracelsus and Brown, it was not for the purpose of accusing or reviling these men, but with the view of investigating their mental history in connection with the systems they professed, and the avowed attitucle of opposition and contempt which they assumed to wards professors of the medical art in general. While I did not shrink from exposing the lamentable errors of doctrine and of conduct into which " system-builders" (as I have called them) naturally fall, I refrained from attempting to deepen the impression by disingenuous sophistry and hysterical ecstacies of praise or blame. The reviewer is much too "smart" a person to take good advice, or I would give him the gentlest possible hint that there are restraints in controversy which gentlemen and men of a liberal profession feel bound to impose on themselves, and which will prevent me from answering him after his own fashion. He will not, of course, accept my view of Hahnemann's character, and he pursues me with all manner of controversial Billingsgate for assailing it. Be it so. It is the way of his sect to please themselves, and depreciate better men, by surrounding Hahnemann with a halo of false glory. This spirit of reckless partizanship does not, however, in the least help the reviewer out of his difficulties. He has, on the contrary, only consummated the proof which I have endeavoured to adduce in the lives of Paracelsus, Brown, and Hahnemann, that from the confirmed system-builder or sectary in physic, nothing is to be expected in the interest of truth. Looking at everything from one point of view, he soon allows the sect to become all in all, and the eternal distinctions of right and wrong go for nothing. It is quite a natural, though a ludicrously small, consequence of such a state of mind, that a casual slip of the pen, made by me on a former occasion (but completely explained and carefully rectified so soon as it was pointed out), takes rank, with this reviewer as a graver offence than selling borax under the name of pnceum !

Take it all in all, no more striking evidence could possibly be given of the utter demoralisation of the Homœopathic ranks, than is contained in this review. That it should be possible to offer to men calling themselves physicians a defence of Hahnemann so completely at variance with the first principles of professional honour, clearly demonstrates the truth of the serere remark made in l'aris the other day, that homocopathy is not a science nor an art (not even a creed nor a doctrine), but simply a trade.

\section{CASES OF FISTULA IN ANO TREATED BY LIGATURE.}

By Draper Mackinder, M.D., F.R.C.S., Gainsborough.

ONE of the most disagreeable companions a man can take about with him is a fistula in ano,-a painfully suggestive associate, that is constantly reminding the sufferer of the very probable existence of an occult and formidable underminer of his health. Even though this remorseless antagonist to comfortable locomotion and repose, instead of being the mere representative of a less conquerable foe, bore with it the tangible evidence of independent responsibility, the consciousness of having to undergo a painful and somewhat dangerous operation, which, in many cases, necessitates the recumbent position for weeks, is of itself sufficient to create anxiety in the strongest mind.

A few weeks incapacity for the performance of the ordinary duties of business-life would, to some people, be a matter of the most serious importance, involving a pecuniary sacrifice amounting almost to ruin. To a needy professional man a prolonged bedroom residence would be peculiarly unfortunate; to the Esculapian most depressing, seeing that it affected materially the welfare of more than the individual sufferer. Any effectual means, therefore, that can be adopted for the avoidance of the series of ill consequences alluded to, instead of being allowed to fall into desuetude, should be hailed as a boon to suffering humanity.

Mr. Luke, of the London Hospital, has revived the treatment of fistula in ano by ligature, an operation that possesses attractions not generally recognised, being without danger, and comparatively painless, creating no alarm, and neither requiring absolute rest nor in-door residence.

To make this proceeding as simple and painless as possible, I requested Mr. Ferguson to make me two very fine silver probes and a grooved director, the probes being seven, and the director five, inches long. One of the probes is blunt, and the other sharp pointed at one end, and both are perforated at the other. These may be easily carried in an ordinary.pocket-case, and will be found useful on many occasions.

Method of Operating. Having, by previously administering an aperient, prepared my patient for the exploration, I introduce the blunt-pointed probe, armed with silk, into the external opening of the fistula, pass the index-finger into the rectum, search for the opening, seize the extremity of the probe (which is easily bent), draw it through the anus, and complete the operation before the sufferer is made aware of the nature of his ailment. In the event of there being no internal opening, or that aperture not being easily found, I pass the sharppointed probe, alone or aided by the director, along the sinus, and transfix the wall of the gut. 'The ordinary probes are too short and thick, and inflict much unnecessary pain.

The following three cases are from my note-book, briefly narrated, and tell their own tale.

CASE 1. Mrs. B., aged 45 , mother of a small family, a stout, full-habited woman, of lymphatic temperament, and in comfortable circumstances, consulted me on the 6th of May, 185\%, for pain at the pit of the stomach, intercostal spaces, and over the dorsal vertebræ, coming on at 3 A.M., and continuing until the erect position was assumed, there being almost complete inability to move. Pressure over one of the upper dorsal vertebræ elicited pain at the point pressed, at the pit of the stomach, and both sides. liest, vesication, mercury with chall, followed by quirine and iron and wine, afforded relief.

On the 20th July she again consulted me, complainirig of left intercostal pain, numbness of left arm, difficulty of turn- 
ing in bed, and tenderness over upper dorsal vertebre, in. areased by pressure. The bowels were constipated. Calomel and oolocynth pills, nitro-hydroobloric aoid, good diet and rest, were successful in affording relief.

On the 2lst of Augant, I was again sont for to examine an sbscess by the side of the amus, whioh had a fine fringe of hæmorrhoids. Suspeoting its true nature, and knowing the bowels had been well opened the previons. day, I at onoe laid open the abscess, from whioh about half an ounce of offensive pus escaped. I introduced my armed blunt probe; tied tho silk, and completed the operation before my patient knew what was the matter with her. The internal opening was about three inches up the rectum, and: between it and the anus $I$ could fiel a large pulsating vessel. I kept her in bed, and under the influence of acetate of ammonia and opium for a few days. 'The ligature came away on September the 4th; no bad symptom was set up, and she bas been in capital hoalth over since.

Case Ir. Mrs. S., a thin, exsanguine woman, who had fool. ishly been suckling her child for the protracted period of two years, sent for $m e$ on the 18th of December, 1857, in consequence of the bursting of an abseess about an inch and a half from the anus, and the discharge of some very stinking matter. Pus had escaped from the bowel for three weeks. Nine months previously she had had a fall against the edge of a stone step; which caused pain at, the cocoyx. The armed, blunt. pointed probe was passed up the sinus to the bowel, about three inches above the sphincter, but no opening could bo found, thongh the probe traversed between the coats of the intestine. A sharp pointed probe was then pushed through the bowel, brought down; and the ligature tied. She was kept. in bed under the influence of acetate of ammonia and opium for a few days; but little disturbance of the natural fnnctions supervened. The ligature came away on January the 8th, and good diet, with gentle exercise, soon established health.

CA8E III. Mr. Sharp, resident surgeon to our dispensary, requested me to operste on him for fistula in areo in August last. He had a flstula, the inferior opening of which was about an inch from the anus, and the superior opening two inches and $\mathrm{s}$ half up the gut. I passed the armed blumt-pointed probe in the manner previously desoribed, and included in the ligature a large pile. The operation was performed in my surgery, and Mr. Sharp afterwards walked home; a distance of some five hundred yards. On the next day, he went to see some of his near patients, and continued to discharge the greater part of his duties-without intermission. The ligature came away on the Bth of September, after which he got much stonter than he had been for some time. Mr. Sharp is a married man, and has passed his fortieth summer; his health has been deteriorating for a considerable time, and he is a martyr to gout and bronohitis; moreover, he is a cripple from early hip-diserse, and has a tumour forming in the long head of the biceps of his right thigh: A more unfavourable case could not easily oceur, and for. such a patient fow surgeons would have recommended the knife. As far as the fistula was concerned, the treatment by ligature is this case was all that could be desired.

Mr. Sharp expresse himself as being much pleased with my manner of proceeding; and has recommended his father to come under my care, the old gentleman having long tolerated \& fundamental nuisance, the surgeon's knife abhorring.

\section{PATHOLOGICAL CONTRIBUTIONS TO MEDICAL JUR1BPRUDENCK.}

By Wruram Boxo Mrshet, M.B.Lond., late Resident Physician at St. Marylebone Infirmary.

III.-Sopor iap8iva into Coma. Extensive Disease of KidNeyg. (IsGestron of OpIUas?).

A. D., aged 64, a washerwoman, was admitted into the Marylebone Intirmary about 10 P.1. on January $19 \mathrm{th}, 1857$. She was cold, pale, and haggard; and I was informed that she had had a fit a short time previously. There was sopor, but not actual coma, as she answered as to her name, when rouserl, but said nothing further. The pulse was 100 , fnll, but weak and compressible. The respirations were $11-12$, noisy, gasping, with lond rdies. The pupils were contracted, and insensible to light. The arcus was very strongly marked. There was con. siderable odema of the feet and legs. The mouth was drawn; but there was no paralysis or convulsion of the limbs. The rattle over the chest prevented the state of the thoracic organs from being acourately determined. The prognosis was evi. dently very unfarourable; as active measures could not be resorted to, on acoount of the mrostration. She was ordered to be wrapped in blankets, to have hot bottles applied to the feet and a blister to the nape; and to have a drop of croton oil and boef.tea.

On the following morning, she was completely comatose The pupils were contracted; the surface warm; the mouth drawn to the left side. The face was somewhat livid. The heart's action was weak and rapid; the pulse almost imperceptible. The a respirations were 18 in $\mathrm{a}$ minute. The bowels had not been opened. About a quart of urine was drawn off: which, contrary to my injunctions, was thrown away. She could not swallow, and was evidently sinking. She died in the evening about 8 P.M., twenty-lwo honrs after admission.

Necropsy sixty-six hours after death. There were no external marks. (Fidems of the legs and feet was present. Riger mortis was tolerably well marked. The pupils were moderately dilated.

Head. The sealp and calcarium were natural. The dura mater was injected. There was some subarachnoid effusion, and two or three ounces of fluid at the base. The arachnoid was opaqne at spots. The large veins of the pia mater were prominent. The brain-substance was bealthy; but the vascular points were more marked and numerous than usual. About the central parts of the brain, the substance appeared a little softer than in health. There was no clot, nor injury to the skull. Serum was found in the lateral ventricles. The vessels at the base were extensively atheromatons.

Chest. The heart weighed sixteen ounces; it was surrounded by fat. There was hrpertrophy of the left ventricle; and the aortic orifice was narrowed from binding down of one of the semilunar valves. The mitral aperture was also con. stricted, although the valve appeared healthy. It almitted but one finger well. The aorta was dilated above the valves. The valves on the right side were healthy. The right auricle ontained a partially decolorised clot, extending into the ven. triele, and interlacing with its fleshy projections. Very little blood was found on the left side of the heart. The coronary arteries were atheromatous. No fluid was fonnd in the pericardium. The lungs were healthy. Tenacious yellow mucus was present in the trachea, bronchi, and their divisions. There was some serous effusion into the right pleara; no adhesions. The left lung was slightly adherent to the costal pleura by recent exudation; and there was effusion into the left side of the chest of some ounces of turbid serum, holding in suspension floceuli of lymph.

Abdomen. The liver was healthy, but pale. The spleen was gmall, firm. The stomach contained some ounces of greenish fluid, without peculiar smell, and much mncus. Its internal surface appeared healthy. The gall-bladder was distended with dark oily bile. The right kidney weighed three onnces; it was small, hard, shrnnker, granular, lobulated, and pake. The capsule separated with difficulty. The left kidney weighed a little over two ounces; it presented the same characters to greater extent. There was much fat around the viscera. Fo fluid was found in the peritoneum. The other organs were natural.

REurarks. In the foregoing case, the pallor of the patient, the colema of the lower extremities, the precession of a fit, with the lethargy, merging into coma, which succeeled, suggested the notion of uræmia from renal disease. The condition of the kidneys, secondary pleuritis, etc., disclosed on inspection, attested the correctness of the conclusion. But it was ascertained, at the investigation, that the woman had drnnk, shortly before the fit, something from a bottle, which she afterwards tlirew away.

The fragment of a bottle was handed to me, and on testing the dried sediment at the bottom with distilled water and tinc. tare of iron, a very evident red colonr was produced (meconate of iron?). Distilled water alone, similarly treated, assumed merely a pale straw colour.

We are consequently compelled to inquire-Did this woman take poison? This is a grave consideration (although all sus. picion of homicide was in this instance fortunately liscarded), as it illnstrates how individuals nffected by more or less re. motely mortal disease, may become the victims of criminal intent, and the effects of the poison administered be masked or modified by the preexistence of certain morbid s:ates, and death therefore attributed to the agency of the former.

Admitting the ingestion of opium - was such a quantity taken as is usually sufficient to cause death; or was its action more 